\title{
Truth predicates, truth bearers, and their variants
}

\author{
Friederike Moltmann ${ }^{1}$
}

Received: 4 March 2017 / Accepted: 16 May 2018

(C) Springer Science+Business Media B.V., part of Springer Nature 2018

\begin{abstract}
Theories of truth can hardly avoid taking into account how truth is expressed in natural language. Existing theories of truth have generally focused on true occurring with that-clauses. This paper takes a closer look at predicates of truth (and related notions) when they apply to objects as the referents of referential noun phrases. It argues that truth predicates and their variants, predicates of correctness, satisfaction and validity, do not apply to propositions (not even with that-clauses), but to a range of attitudinal and modal objects, objects we refer to as 'claims', 'beliefs', 'judgments', 'demands', 'promises, 'obligations' etc. As such natural language reflects a notion of truth that is primarily a normative notion, which, however, is not action-guiding, but rather constitutive of representational objects, independently of any actions that may go along with them. The paper furthermore argues that the predicate true is part of a larger class of satisfaction predicates whose semantic differences are best accounted for in terms of a truthmaker theory along the lines of Fine's (A companion to the philosophy of language, Wiley, Chichester, 2017b) truthmaker semantics. Truthmaker theory also provides a notion of partial content for attitudinal and modal objects, which may exhibit partial correctness, partial satisfaction, and partial validity.
\end{abstract}

Keywords Truth · Truthmaker · Propositions · Partial content - Satisfaction · Correctness $\cdot$ Normativity

\footnotetext{
Friederike Moltmann

fmoltmann@univ-paris1.fr

1 CNRS-IHPST, Paris, France
}

Published online: 19 June 2018 


\section{Introduction}

Natural language bears on a range of philosophical issues, and it fails to bear on others. The notion of truth is certainly one on which natural language bears a lot. Many theories of truth are focused on the way truth is conveyed in natural language, on the syntactic status of true as a predicate, connective, operator, or other linguistic 'device', as well as on the sorts of object that true, if considered a predicate, applies to, whether it is a proposition, an utterance, an act, or some other kind of object. Theories of truth generally care about what sorts of expressions true goes along with, that-clauses, referential NPs, quantifiers, or pronouns. Thus, a focus on true with thatclauses has given rise to views according to which true does not act as a predicate or express a property, but rather has the status of a connective or operator (Mulligan 2010), an anaphoric device (Grover et al. 1975), or a semantically empty predicate, which may just serve the purpose of stating generalizations regarding propositional contents using quantifiers or pronouns (Ramsey 1927; Horwich 1990; Künne 2003 among others). Clearly then, a closer look at the way the expression true actually applies in natural language can be very important for the philosophical debate itself. This paper argues that a closer look at both semantic and syntactic aspects of natural language is very important for three issues regarding the notion of truth:

[1] the nature and range of truth bearers

[2] the relation of truth to normativity and the broader notion of satisfaction

[3] the actual semantics of truth predicates with that-clauses.

Whereas most work on the expression of truth focuses on true with that-clauses, this paper focuses on true as a predicate that clearly applies to objects, as the referents of referential noun phrases. Moreover, it focuses on the fact that there is not a single truth predicate true, but a range of predicates that convey truth or a truth-related notion. Truth-related predicates consist in predicates of correctness, of satisfaction, and of validity.

Truth-related predicates, including true, are not predicates of a single sort of object, say propositions. Rather in natural language they act as predicates of various attitudinal objects. Attitudinal objects are, for example, entities that we refer to as claims, judgments, beliefs, requests, promises, decisions, intentions, and desires. Even though hardly recognized as such in contemporary metaphysics, attitudinal objects are extremely well-reflected in natural language and display a range of common characteristics which together distinguish them from other categories of objects, in particular acts and propositions. Some attitudinal objects are mental states (beliefs, intentions, desires), others are the non-enduring products of actions in the sense of Twardowski (1911), for example judgments, decisions, claims, promises, and requests. Predicates of satisfaction also apply to objects closely related to attitudinal objects, namely (deontic) modal objects. Modal objects, which share relevant characteristics with attitudinal objects, are entities like obligations, permissions, needs, and invitations, as well as laws and rules. Both attitudinal and modal objects are part of the ontology of natural language in the sense of Moltmann (2017b, to appear), namely as the ontology speakers implicitly accept when using the language. That ontology may be different from 
the reflective ontology of speakers, the ontology philosophers or non-philosophers may accept when thinking about what there is.

Correct conveys truth (and just truth) with a range of attitudinal objects, as a norm associated with representational objects, rather than one that guides cognitive or illocutionary acts (Jarvis 2012). The range of attitudinal objects with which correct conveys truth, it turns out, is greater than the one that true can apply to (which shows a surprising discrepancy between the philosophical notion of truth and the semantic content of the English expression true).

Predicates of satisfaction (satisfied, fulfilled, taken up, implemented, realized etc) are on a par with truth predicates, applying to particular sorts of attitudinal and modal objects. But different satisfaction predicates impose different conditions on attitudinal and modal objects and their satisfiers, conditions that can best be formulated in terms of a truthmaker approach along the lines of Fine (2017b, to appear a, b). Truthmaker theory will also account for the part structure of attitudinal and modal objects, which is based on partial content and underlies notions of partial truth, partial satisfaction, and partial validity.

Not only truth predicates with referential noun phrases apply to attitudinal (and modal) objects, but also truth predicates with that-clauses, which, the paper argues, apply to a contextually given claim or suggestion, rather than, as is standardly assumed, an abstract proposition.

With its focus on a greater class of truth bearers and truth-related predicates, the paper, finally, will add new arguments against a deflationist or minimalist account of truth predicates with that-clauses.

\subsection{Propositions, attitudinal objects, and the core-periphery distinction}

Philosophical theories of truth generally focus on true when it occurs with a that-clause as in (1a):

(1) a. That Paris is the capital of France is true.

That-clauses are generally considered to be proposition-referring terms, which appears supported by the apparent equivalence of (1a) and (1b):

(1) b. The proposition that Paris is the capital of France is true.

The focus of this paper is on true and other truth-related predicates when they occur with referential NPs rather than that-clauses. This point of departure will lead to a rejection of an analysis of (1a) as in (1b) and establish a different category of objects than propositions as the primary bearers of truth-related predicates.

Of course, true applies to a referential NP in (1b) and this raises the question whether it would not simply establish that true applies to propositions. However, there are good reasons not to focus on sentences like (1b). It is significant that philosophers arguing for propositions being truth bearers hardly appeal to sentences like (1b), but rather to sentences with simple that-clauses as in (1a) (Sect. 7) (and similarly for the role of propositions as the objects of attitudes). Why don't sentences like (1b) qualify for supporting propositions as objects playing a particular role in the semantics of natural language, such as truth bearers? That is because such sentences do not 
belong to the relevant part of language, namely what one may call its core, the part of language whose use does not require philosophical reflection, yet may reflect an implicit philosophically relevant view. The proposition that $\mathrm{S}$ is a quasi-technical term aiming to make explicit (and thus likely reifying) what that-clauses are supposed to stand for. ${ }^{1}$ As a term that involves a certain amount of philosophical or linguistic reflection, it belongs to what one may call the periphery of language, the part of language that does presuppose such reflection. ${ }^{2}$

While the core-periphery distinction in this sense has hardly ever been made explicit, it constitutes an implicit assumption that has guided the appeal to natural language throughout the history of philosophy. That is, it constitutes an implicit assumption on which natural language ontology as a philosophical practice throughout history is based and without which the project of natural language ontology would not be possible (Moltmann 2017b, to appear). The distinction is well-reflected in the choice of examples philosophers use or refrain from using when arguing for a particular ontological category. For example, Frege, when arguing for propositions and numbers being objects, pointed at the apparent semantic function of that-clauses and at the apparent number-referring function of terms like nine and the number of planets, terms from the core of language. He did not appeal to terms like the proposition that $\mathrm{S}$ or the number nine, which are reifying terms in the periphery of language and thus could not make the point. Similarly, when philosophers debate whether natural language involves reference to properties as abstract objects, they do not point at the existence in English of terms like the property of being wise, which are terms in the periphery of language, but rather at simple nominalizations such as wisdom, which belong the core of language. While the core-periphery distinction certainly is in need of further clarification, it is incontestable that it guides philosophers' appeal to natural language when arguing for an ontological category, and without it, descriptive metaphysics could hardly be pursued.

Referential NPs that are clearly part of the core of language and go with the predicate true include ordinary nominalizations of attitude verbs such as belief, judgment, and claim:

(2) a. John's belief that $\mathrm{S}$ is true.

b. John's judgment that $S$ is true.

c. John's claim that $\mathrm{S}$ is true.

The standard, proposition-based view takes nouns like judgment and claim to be ambiguous between standing for mental events or speech acts and standing for propositions (see, for example, Pustejovsky 1995; Thomson 2008). That assumption is meant to account for the observation that such predicates allow on the one hand for content-

\footnotetext{
1 Other 'reifying terms' of this sort include the truth value true and the direction north, again terms no philosopher would point to when arguing for truth values or directions being objects. Frege, of course, argued for truth values being objects, but he did so on the basis of considerations of the meaning of sentences, not on the basis of the availability of the term the truth value true in natural language. Frege's motivations for truth values being objects in fact did not come from what appears to be reflected in natural language, unlike his motivations for numbers and propositions.

2 For the ontological distinction between core and periphery of language (which is quite distinct from the Chomskian distinction of the same name) see Moltmann (2013a; 2017b, to appear).
} 
related predicates such as true (which could apply to propositions) and on the other hand for predicates of concreteness, specifying, for example, a temporal duration or causal relation. However, there are good reasons to consider such nouns univocal, standing for entities of a third kind, what I call attitudinal objects (Moltmann 2003b, 2013a, c, 2014, 2017c). On reason is that they permit at once predicates concrete objects and truth predicates ${ }^{3}$ :

(3) a. John remembered his false judgment that S.

b. Mary overheard John's true claim that $S$.

Another, more important reason is the applicability of various predicates (with a particular reading) to propositions, actions, and attitudinal objects. Beliefs, judgments, and claims belong to a category of objects - the category of attitudinal objects-which have a range of linguistically well-reflected characteristics that together distinguish them both from propositions and from actions.

First, there are predicates of satisfaction that can apply to a request, a piece of advice, or a promise, but could apply neither to an action nor a proposition (Ulrich 1976; Moltmann 2014, 2017c):

(4) a. John fulfilled the request.

b. ??? John fulfilled the act of requesting/a proposition.

(5) a. Joe followed the advice.

b. ??? Joe followed the act of advising/a proposition.

(6) a. John broke the promise.

b. ??? John broke the act of promising/a proposition.

The applicability of predicates of satisfaction makes particularly clear that nouns like request, advice, promise etc. could not stand for acts or propositions: neither acts nor propositions can be 'fulfilled', 'satisfied', 'followed', or 'broken', a point emphasized by Ulrich (1976).

Attitudinal objects generally come with essential truth or satisfaction conditions, and of different sorts, reflected in the applicability of different satisfaction predicates. $^{4}$ Those conditions involve conditions on the truthmakers/satisfiers (or falsemakers/violators) of attitudinal objects and the setting of norms underlying the direction of fit, conditions that make a separation of content and force unnecessary (Sect. 3).

Second, attitudinal objects have a part structure based on partial content. This also distinguishes them from states, on the standard understanding on which states have temporal parts. A part of a belief, judgment, or assertion is a partial content, not the temporal part of a state or act. That is the only way part of can be understood when

\footnotetext{
3 These are not ordinary cases of co-predication dealt with in the pertinent literature (Pustejovsky 1995, Asher 2010). This literature focuses on conjunction of predicates of different sorts, allowing conjuncts to apply to different developments of an underspecified entity referred to by the subject term. Compositionally such an account would not be available in $(3 \mathrm{a}, \mathrm{b})$, which requires a modifier to apply to the semantic value of the noun and then the predicate to apply to the modifier-noun combination.

4 Not all attitudinal objects come with truth or satisfaction conditions. There are also 'expressive' attitudinal objects, for example products of expressive illocutionary acts such as sighs and complaints.
} 
applied to a belief, judgment, or assertion. ${ }^{5}$ By contrast, part of does not really apply to propositions, with a clear intuitive understanding. ${ }^{6}$ With propositions, it very much depends on the theoretical conception of a proposition how part of is understood. If propositions are conceived as structured propositions, then objects and properties will be constituents of propositions, and hence parts of them. But not so if propositions are conceived as sets of possible worlds or constructs from possible worlds, in which case the notion of part may be construed as that of partial content (Yablo 2015) (or, similarly, if propositions are conceived in terms of sets of truthmakers or satisfiers as in Fine (2017b)). ${ }^{7}$

Finally, attitudinal objects enter similarity relations strictly on the basis of being the same in content, provided they are of the same type (Moltmann 2014, 2017b). This is reflected in the way the same as and partly the same as are understood below:

(7) a. John's claim was the same as Mary's.

b. John's claim was partly the same as Mary's.

(7a) can only state the sharing of content, not the sharing of a way of performing a speech act. (7b) similarly can only be about the sharing of a partial content. This is different for actions. For actions to be the same, they need to share features of their performance; sharing of content is neither sufficient nor in fact necessary.

Thus, attitudinal objects have the following general characteristics:

[1] they have truth or satisfaction conditions

[2] they have a part structure based on partial content

[3] they enter similarity relations based on content only rather than shared features of a performance.

These features together characterize attitudinal objects as an ontological category and distinguish them from acts and propositions. They also distinguish them from states, on a notion of a state on which a state has temporal parts and enters similarity relations based on shared features of its temporal parts. States in that sense generally do not come with satisfaction conditions. ${ }^{8}$

5 All part-related expressions, not just part of behave that way (most of, to some extent, partially etc.).

6 Part of also applies to what is described as a 'content', picking out a partial content:

(i) a. Part of the content of the sentence John came and Mary left is that John came.

b. Part of the content of the claim/the thought that John came and Mary left is that John came.

7 Note that the adverbial partly can apply to propositions clearly relating to a partial content, as seen in (ia), as opposed to (ib) (which does not have a clear meaning):

(i) a.The proposition that John is incompetent is partly true.

b. Part of the proposition that John is incompetent is true.

However, partly does not directly relate to the part structure of the subject referent, but may relate to an entity closely related to it, such as the content of a sentence, as in (iia), which is not equivalent to (iib):

(ii) a. The sentence John is incompetent is partly true.

b. Part of the sentence John is incompetent is true.

See Yablo (2015) for the observation and Moltmann (2017a) for an analysis.

8 The sortal state generally is used for states in that sense rather than for attitudinal objects of the sort of beliefs, desires, or intentions. 
In addition to those content-related features, attitudinal objects, as mentioned, may exhibit properties of concreteness. They may enter causal relations (content-based mental causation) and have a limited lifespan, generally not lasting longer than the acts that may have established them.

Attitudinal objects depend on a particular agent. Thus, John's claim depends on John and cannot be the claim of Mary. This raises the question how attitudinal objects would allow for the sharing of content. One way in which content can be shared, obviously, consists in two agents engaging in similar attitudinal objects. Another way consists in two agents engaging in a kind of attitudinal object. Kinds of attitudinal objects are equally well-reflected in natural language (Moltmann 2003b, 2013a). Whereas John's claim that $\mathrm{S}$ in (8a) stands for a particular attitudinal object, the claim that $\mathrm{S}$ in (8b) stands for a kind of attitudinal object:

(8) a. John's claim that $S$ is true.

b. The claim that $\mathrm{S}$ is true/is widely believed/has never been made.

As (8b) illustrates, kinds of attitudinal objects exhibit representational properties just like particular attitudinal objects; moreover they need not be instantiated.

While attitudinal objects are hardly recognized in contemporary metaphysics, they are clearly part of the ontology of natural language (Moltmann 2003a, b, 2013a, 2014, 2017c). Natural language generally displays a wealth of (nontechnical) terms for attitudinal objects, most importantly nominalizations of attitude verbs such as claim, thought, judgment, decision, promise, offer, invitation, request, demand, suggestion, desire, intention, belief, hope, fear, etc., which exhibit a stable semantic behavior displaying the characteristic properties of attitudinal objects. The fact that attitudinal objects are well-reflected in language does not mean that attitudinal objects themselves are in any way language-dependent. They would exist whether or not a language has terms standing for them. It is just that language displays them and their nature better than our reflective ontology. Attitudinal objects divide into mental states (beliefs, intentions, desires), cognitive products (decisions, judgments, thoughts), and illocutionary products (claims, requests, promises), in roughly the sense of Twardowski's (1911) distinction between actions and products. According to that notion of a product, a claim is the non enduring product of an act of claiming, a judgment the (nonphysical) product of an act of judging, and a decision the (nonphysical) product of an act of deciding. To use Thomasson's (1999) term, the judgment is the 'abstract artifact' that results from an act of judging, in Thomasson's sense of 'abstract' as 'lacking a physical realization' (Moltmann 2014, 2017c). As in the case of artifacts, it is the product, not the act that is the carrier of representational and relevant normative properties. This is very important for the notion of truth and truth-related notions. Attitudinal objects, not actions that may have established them, are the bearers of truth or the related notion of satisfaction.

To summarize, attitudinal objects are entities that are characterized by a range of properties, and they are well-reflected in natural language, at least in English and other European languages. They consist of mental states and the non-enduring products of mental or illocutionary acts. As such they exist whether or not a language has terms for them. 


\section{True and correct as truth predicates}

\subsection{Correctness and the norm of truth}

An important observation is that the truth of attitudinal objects can also be conveyed by correct (or right), which thus acts as a normative truth predicate:

(9) a. John's belief that $\mathrm{S}$ is correct.

b. John's judgment that $\mathrm{S}$ is correct.

c. John's claim that $\mathrm{S}$ is correct.

In natural language, correct when applied to a belief or an assertion conveys just truth, whether or not the belief or assertion is justified or warranted. This is an important fact. Even if some philosophers such as Williamson (2000) impose further, epistemic conditions on the correctness of beliefs or assertion, this could not influence the application of correct in natural language. ${ }^{9}$ Correct simply cannot convey more than just truth when applied to beliefs, judgments, and assertions.

Like true, correct can also be predicated of sentences:

(10) This sentence is correct.

When predicated of sentences, however, correct evaluates grammaticality rather than truth. Here the more general normative meaning of correct is at play, where correct holds of an object $o$ just in case $o$ fulfills the norm (or standard of correctness) that is associated with $o$ or that is relevant in the context. The norm associated with a syntactic object is grammaticality rather than truth. Other kinds of norms are associated with other types of objects that correct may apply to. A choreography may be the norm for a dancer's movement as in (11a), a logic that for a proof as in (11b) and (11c), and laws or moral values for punishments as in (11d):

(11) a. The dancer's movements were correct.

b. The proof was correct. ${ }^{10}$

c. The conclusion that Mary is guilty is correct.

d. John's punishment was correct.

For the application of correct, as for other truth-related predicates, the distinction between actions and their products is important. When a conclusion is correct, the act of concluding itself need not be; it may go against a contextually given demand-just

\footnotetext{
9 Thomson (2008) argues that correct applies to assertions in two different ways, depending on the meaning of assertion. When assertion stands for a proposition, correct conveys external correctness, such as truth; when assertion stands for an act of asserting, it conveys internal correctness, correct pronounciation, or use of a grammatical sentence for example. I do not think this is reflected in the linguistic intuitions. Thomson relies on the standard view according to which assertion is polysemous. But that view, as we have seen, is problematic.

10 One may argue that proofs are correct by nature. Assertions and questions about the existence of a proof of a hypothesis seem to presuppose that. However, proof is in fact also used as a noun for something that may or may not be correct (the proof he wrote down turned out to be incorrect, it contained a mistake). Of course, the verb prove is factive: John proved that $\mathrm{S}$ implies the truth of $\mathrm{S}$-- as well as the existence of a (correct) proof. But the verb is not the noun and the noun appears to be polysemous, able to also stand for 'real' as well as 'potential' or attempted proofs. See also Löf (1987).
} 
like a signature may be correct, but not the act of signing. This also holds for assertions and judgments. When (9c) is true, (12a) need not be, and vice versa, and similarly for (9b) and (12b):

(12) a. John's making a claim that S/John's claiming (that $S$ ) was correct.

b. John's making a judgment (that $S$ ) is correct. ${ }^{11}$

Correct in (9a, b, c) conveys truth; in (12a, b) it conveys the fulfillment of what may just be a contextually given norm, a requirement, expectation, instruction, or purpose. Acts of making an assertion or a judgment or adopting or maintaining a belief may be correct because they follow an instruction or order, not because they capture or maintain a truth. Assertions, judgements, and beliefs, by contrast, are not evaluated as correct according to some contextually relevant norm, but only according to the norm they are intrinsically associated with, the norm of truth. Acts of judging and asserting may produce a product that is associated with the norm of truth, quite independently of what norms the acts themselves may aim to satisfy. ${ }^{12}$

In the philosophical literature, normativity is generally linked to actions. Thus, there are proposals according to which truth is constitutive of the norm associated with believing, along the lines of 'if one ought to believe $\mathrm{p}$, then $\mathrm{p}^{\text {' (Boghossian }}$ 2003; Gibbard 2005). But such conditions on adopting or maintaining a belief are problematic (Glüer and Wikforss 2009). Truth is not the aim of believing in the sense in which the fulfillment of moral values is what certain types of actions and decisions should aim for. In fact, the norms for actions of adopting or maintaining a belief may simply be contextually given norms of some sort or another. Truth as a norm is not action-guiding, but rather is solely associated with the representational object, as its purpose or 'telos', as Jarvis (2012) puts it. As a teleological norm, truth is associated with mental states like beliefs as well as products of mental or illocutionary acts such as judgments and assertions. Mental states such as beliefs and intentions need not have been produced at all by any mental acts aiming at anything. In fact, intentions as states arguably are prior to any intentional acts (Searle 1983).

To summarize, then, correct applies to an object with a single reading just in case the object is intrinsically associated with a particular norm. Correct applies to beliefs, judgments, and claims with a single reading conveying truth because beliefs, judgments, and claims are intrinsically associated with the norm of truth. This association

\footnotetext{
11 It was pointed out to me that judging is not really a voluntary action, which means that a judging cannot be correct in the way a claiming can. However, one can refrain from making a judgment, and thus the making of a judgment can be correct.

12 Thomson (2008) argues against truth being normative and correct conveying normativity. Rather, for her, correct applies relative to a kind that fixes the standard that an object of that kind has to meet in order to count as correct. This is entirely in the spirit of the present account on which truth is the standard associated with a certain kind of attitudinal object, which an attitudinal object of that kind needs to meet if it is to count as correct. Unlike the present view, Thomason does not take contextually given standards into consideration. Rather she takes the norms or standards associated with acts (of asserting) to be standards of 'internal correctness'.

For Thomson, assertions are associated with external and with internal standards of correctness, and truth is just one (external) standard that assertions are associated with. That is because on her view assertion is ambiguous between denoting a proposition (associated with an external standard of correctness) and denoting an action (associated with an internal standard of correctness), a view that I take to be in error (Sect. 1). See also Fn 9.
} 
is quite different from the contextually given norms that actions of judging or claiming as well as actions of adopting or maintaining a belief are associated with.

Conveying truth (and only truth) with beliefs, judgments, and assertions does not seem to be a peculiarity of English correct. Other normative predicates in English do as well, for example right and, for falsehood, wrong, as do corresponding predicates in other European languages. ${ }^{13}$ German stimmen, for example, is a predicate that expresses a more restricted notion of correctness, relating to norms of the sort of prescriptions and rules, but not moral values, as seen in (13a); yet it conveys truth (and only truth) with assertions and suppositions, as in (13b) (Moltmann 2015a):

(13) a. Der Tanzschritt/??? Die Bestrafung stimmt.

'The dance step/The punishment is correct'

b. Die Aussage/Die Annahme stimmt.

'The claim/The supposition is correct'.

The fact that two linguistically unrelated predicates convey truth for the very same range of objects (truth-directed attitudinal objects) suggests that it may be a crosslinguistic universal that predicates of correctness convey truth and just truth when applied to attitudinal objects like beliefs, judgments, and claims, a speculation that of course awaits further crosslinguistic research.

Propositions hardly allow for the application of correct, in marked contrast to beliefs and assertions ${ }^{14,15}$ :

(14) ??? The proposition that Mary left is correct.

If propositions are reified meanings of sentences, their ability to be truth bearers should be derivative and not due to the truth norm that is constitutive of the intentionality of beliefs and products of acts of judging and claiming. The predicate true differs

13 Sometimes a language displays only the normative predicate and no specific truth predicate. Thus, German has only falsch, the antonym of richtig 'correct', conveying mere falsehood with claims and beliefs, but, for example, failure to follow the choreography with dance movements (Moltmann 2015a).

Interestingly, falsch when predicated of sentences as in (ia) is not ambiguous, but means only 'false', not 'grammatically wrong'. To convey ungrammatically requires explicitly negating korrekt or richtig:

(i) a. Der Satz ist falsch.

'The sentence is false.'

b. Der Satz ist nicht richtig/nicht korrekt/inkorrekt.

'The sentence is not right/not correct/incorrect.'

14 There are other cases where true is appropriate, but not correct:

(i) a. The story the children were told is true.

b. ?? The story the children were told is correct.

These seem to be cases where truth is secondary for the purpose or telos of the representational object, that is, where truth does not act as a norm associated with the representational object.

15 Propositions as truth bearers are sometimes considered on a par with entities like theories and dogmas. However, unlike propositions, theories and dogmas are artifacts that have been established at a particular time or time period. Whereas theories are generally dependent on a particular agent, dogmas involve a generic dependency (see Thomasson 1999 for the notion of artifacts dependent on generic agency). Unlike particular attitudinal objects, theories and dogmas have the status of enduring and shared contents, because of the range of causal chains and physical realizations they involve. Theories and dogmas can be 'true' as well as 'correct', like truth-directed attitudinal objects and unlike propositions. 
from correct in conveying a representation-related notion that can apply to sentences and abstract propositions. This notion may then be accounted for in terms of the primary notion of truth that is part of the notion of correctness. Roughly, true will hold of a proposition or sentence in virtue of that proposition or sentence being able to characterize a (potential) belief or claim that fulfills its norm. ${ }^{16}$

\subsection{Correctness and the reflective notion of truth}

There is another important point that the actual semantic behavior of correct makes. With a range of attitudinal objects only correct is applicable, not true, even if those attitudinal objects would be regarded as truth bearers, given our reflective (and not just philosophical) notion of truth, that is, the notion speakers adopt upon reflection, not the notion they implicitly adopt when using natural language. The judgments are less sharp in English, though, than they are in other European languages, such as German, French, and Italian.

First, attitudinal objects with a merely speculative force allow for correct, but generally resist true, for at least a range of English speakers:

(15) a. John's guess that Mary is won is correct.

b. ?? John's guess that Mary won is true.

(16) a. The suspicion that Mary is guilty is correct.

b. ?? The suspicion that Mary is guilty is true.

(17) a. The speculation/conjecture that Mary is guilty was correct.

b. ?? The speculation/conjecture that Mary is guilty was true.

(18) a. The calculation that Mary would be home by then was correct.

b. ?? The calculation that Mary would be home by then was true.

Corresponding judgments from other European languages (such as French, Italian, and German) are considerably sharper. Thus, in German, wahr ('true') is clearly excluded from speculative attitudinal objects, just as vrai and vero are in French and Italian respectively. This is illustrated below by the German, French and Italian translations of $(15 \mathrm{a}, \mathrm{b})$ and $(16 \mathrm{a}, \mathrm{b})$ :

(19) a. Die Vermutung, daß Maria gewonnen hat, ist richtig/??? wahr.

b. L'hypothèse que Marie ait vaincu est correcte/??? vraie.

c. La supposizione que Maria abbia vinto è corretta/??? vera.

(20) a. Der Verdacht, daß Maria schuldig ist, ist richtig/??? wahr.

b'. Le soupçon que Marie soit culpable est correct/??? vrai.

c. Il sospetto que Maria sia culpabile è corretto/??? vero.

Also future-oriented attitudinal objects do not easily accept true as a predicate, but are better with the predicate correct. Again, the data are stronger in German than in English $^{17}$ :

\footnotetext{
16 Note that the belief or claim may just be a kind and thus lack actual instances.

17 Predictions, though, can 'become' true:
} 
(21) a. Die Vorhersage, daß es gestern regnen würde, war richtig.

'The prediction that it would rain yesterday was correct.'

b. ??? Die Vorhersage, daß es gestern regnen würde, war wahr.

'The prediction that it would rain yesterday was true.'

Furthermore, cognitive products that result from perception do not allow for true, and here the judgments are as sharp in English $(22,23)$ as they are in German in (24):

(22) a. Mary's impression was correct.

b. ??? Mary's impression was true.

(23) a. Mary's observation that it is raining $\mathrm{S}$ is correct.

b. ??? Mary's observation that it is raining is true.

(24) a. Marias Eindruck ist korrekt/??? wahr.

'Mary's impression is correct/true.'

b. Marias Beobachtung, daß es regnet, ist richtig/??? wahr.

'The observation that it is raining is correct/true.'

Recollections may be viewed on a par with products of perception, namely as products of introspection. They also do not accept true, but only correct, and that in English and German:

(25) a. ??? Mary's recollection that it had rained on her birthday a year ago is true.

b. Mary's recollection that it had rained on her birthday a year ago is correct.

(26) Marias Erinnerung ist richtig/?? wahr.

'Mary's recollection is correct/true.'

Footnote 17 continued

(i) The prediction that it would rain yesterday had become true.

Even when speaking about a prediction in the past, had become true or turned out to be true are appropriate, not, was true. Future-oriented attitudinal objects thus change over time as regards their ability to bear truth, though not as regards their ability to bear correctness. A prediction is correct just in case it is true at some point in the future. This suggests that the norm associated with correctness applied to an attitudinal object at a time $t$ is truth at some time, rather than truth at $t$.

Interestingly, as a referee has pointed out, true may sound better with prediction when acting as a noun modifier, as in a true prediction. The reason for that may be that the adjective here is part of a reduced relative clause, derived from something like prediction that has become true.

This also seems to hold for some speculative attitudinal objects. Thus German Hypothese 'hypothesis' does not really accept ist wahr 'is true' as predicate, but for some speakers is acceptable with wahr as a modifier:

(ii) a. ??? Die Hypothese ist wahr.

'The hypothesis is true.'

b. eine wahre Hypothese

'a true hypothesis'

Hypothese also accepts hat sich als wahr herausegestellt 'turned out to be true':

(iii) Die Hypothese hat sich als wahr herausgestellt.

This indicates that wahr in (iib) involves a reduced relative clause with hat sich als wahr herausgestellt as predicate. 
Correct rather than true also applies to truth bearers like explanations and answers, which require particular presuppositions to be fulfilled, as in (27a) and (28a). Again the judgments are somewhat sharper for the German translations in (27b) and (28b):

(27) a. The explanation that Mary was not informed was correct/?? true.

b. Die Erklärung, daß Maria nicht informiert war, war richtig/??? wahr.

(28) a. The answer that Paris is the capital of France is correct/? true.

b. Die Antwort, daß Paris die Hauptstadt von Frankreich ist, ist richtig/??? wahr.

For an explanation to be a correct or incorrect explanation, it does not suffice for its content to be true; the explanation also needs to explain what is to be explained. Similarly, an answer needs to respond to the question for it to be correct or incorrect.

True unlike correct thus requires an intentionally maintained or produced attitudinal object that has a certain strength of truth-directed force and that need not to respond to another attitudinal object (in terms of explanation or answerhood). True thus carries a significant presupposition that correct lacks. True then does not actually convey the reflective or philosophical notion of truth. That is, true does not convey the notion of truth of ordinary speakers or philosophers when they reflect upon that notion. Rather true conveys a notion of truth that speakers implicitly accept when they use the language. Only correct conveys the reflective or philosophical notion of truth, and only when applied to objects intrinsically associated with the norm of truth, attitudinal objects ranging from beliefs and assertions to speculations, suggestions, and impressions.

There is thus a discrepancy between a philosophical or reflective notion of truth and the notion conveyed by the corresponding natural language expression. There are other cases of such a discrepancy between a notion that speakers may adopt upon reflection and a notion conveyed by the corresponding natural language expression. The notion of existence is such a case. The notion of existence in contemporary philosophy is generally considered a univocal concept that trivially applies to all actual entities of whatever sort, whether existence is conceived of as existential quantification or as a property. By contrast, the predicate exist in English (and it is syntactically a predicate) applies only to (actual) enduring and abstract objects. Exist in particular fails to apply to events (which rather 'happen', 'take place', or 'occur') (Hacker 1982; Cresswell 1986; Moltmann 2013c). This holds not only for ordinary speakers, but also for philosophers when they use English, whatever their metaphysical views about existence may be. The philosophical or reflective notion of existence (the one that a philosopher or even nonphilosopher may adopt upon reflection) thus diverges from the one that is part of the semantics or rather the metaphysics of natural language.

Discrepancies of this sort require acknowledging two layers of judgements: that of linguistically reflected intuitions and that arising from a shared philosophical or reflective notion. Both types of judgment belong to the subject matter of descriptive metaphysics in Strawson's (1959) sense. ${ }^{18}$ Only the former, however, belong to the subject matter of natural language ontology in the sense of Moltmann (2017b). The

18 Fine (2017a) uses the term 'naïve metaphysics' and 'metaphysics of appearances' for descriptive metaphysics, properly understood. 
latter belong to the branch of metaphysics whose subject matter is common sense judgments that speakers would explicitly endorse and that may be part of their shared, perhaps naïve, metaphysical reflections.

\section{Predicates of satisfaction}

\subsection{Truth conditions versus satisfaction conditions and the notion of direction of fit}

Truth is part of another more general notion, namely satisfaction. Various types of attitudinal objects do not have truth conditions, but rather satisfaction conditions, or in fact satisfaction and violation conditions. ${ }^{19}$ Satisfaction (and violation) conditions in turn divide into different sorts, expressed by different natural language predicates. Thus, illocutionary products that are requests, demands, promises, pieces of advice, or permissions cannot be said to be 'true'. ${ }^{20}$ But they can be 'satisfied', 'fulfilled', 'complied with', 'kept', 'followed', or 'taken up'. Moreover, a demand or a promise cannot be 'false'. A demand would rather be 'ignored' or 'contravened' and a promise 'broken'. Similarly, cognitive products like decisions cannot be said to be 'true', but rather would perhaps be 'implemented' or 'executed'. Finally, mental states such as desires and intentions could not be said to be 'true', but they can be 'fulfilled' or 'realized'.

What is special about all these attitudinal objects is that they come with what Searle $(1969,1983)$ calls a 'world-word/mind-direction of fit', rather than a 'word/mindworld direction of fit'. They require the world to fit the representation, rather than the representation to fit the world.

The notion of direction of fit is generally used as an intuitive notion and as such applies to illocutionary products (or speech acts) such as assertions and requests rather straightforwardly. However, its application to mental products and states such as hopes and fears is less straightforward and requires a clarification of the notion. I will come back to that later.

In its application to illocutionary products, the direction of fit is a normative notion whose normativity is reflected in attributions of correctness in the following way. An illocutionary product with a word-world direction of fit is correct in case there is a part of the world that makes it true. An action performed in recognition of an illocutionary product with a world-word direction is correct in case it satisfies the illocutionary product. ${ }^{21}$ A word-world direction of fit means that the illocutionary product itself needs to fulfil a norm. Illocutionary products with a world-word/mind direction of fit

\footnotetext{
19 In intuitionism, truth is in fact replaced by (or explained in terms of) satisfaction. Thus, rather than taking propositions to consist in truth conditions, they are taken to consist in an expectation or intention that is to be fulfilled by a proof (or evidence) (Heyting) or else in a problem or task to be resolved by a proof (or evidence) (Kolmogorov) (Löf 1987, p. 410).

20 A promise, of course, can be said to be a true promise or a false promise, but only in the sense of being made sincerely, not in the sense of being fulfilled.

21 'In recognition of' is meant to capture Searle's (1983) point that only actions by way of satisfying a request or intention can satisfy the request or intention.
} 
come, by contrast, with an action-guiding norm or purpose. This is made more explicit below:

(29) Characterization of direction of fit applied to illocutionary products

i. An illocutionary product $o$ has a word-world direction of fit just in case $o$ satisfies its intrinsic norm (is correct) in a world $w$ iff $w$ makes $o$ true.

ii. An illocutionary product $o$ has a world-word direction of fit just in case any action $a$ performed in recognition of $o$ satisfies the norm imposed by $o$ (is correct) in a world $w$ iff $a$ is part of $w$ and satisfies $o$.

Correct fails to convey satisfaction when applied to attitudinal objects that come with a world-word direction of fit. A request cannot be 'correct' (in the sense of being satisfied), though it can be 'correctly satisfied'. ${ }^{22,23}$ This should be attributed to the particular normative nature of a world-word direction of fit, which imposes a norm on actions performed in recognition of the representational object, but not on the representational object itself, in contrast to a word-world direction of fit.

Satisfaction conditions go along best with a truthmaker approach along the lines of Fine (2017b, to appear a, b). This means that not entire worlds stand in the satisfaction relation to a request, promise, intention, or decision, but rather relevant parts of the world, in particular actions. Actions as satisfiers of a request, promise, intention, or decision are entities that are wholly relevant for the satisfaction of the request, promise, intention, or decision. They are exact satisfiers of the request, promise, intention, or decision. Some attitudinal objects, for example requests or promises, also have (exact) violators, actions in virtue of which the attitudinal object fails to be satisfied. For products of directive illocutionary acts, satisfaction (or violation) may also be conveyed by agentive verbs, with the by-locution describing a particular action as the satisfier (or violator) of the attitudinal object:

(30) a. John fulfilled the demand by handing in the paper in time.

b. John followed/ignored the request by staying home.

The truthmaker approach also applies to truth-directed attitudinal objects such as beliefs, judgments, and claims. That means that a situation will be the (exact) truthmaker of a belief, judgment, or claim just in case it is wholly relevant for the truth of the belief, judgment, or claim.

In Fine's (2017b, to appear a, b) truthmaker semantics, the notions of exact truthmaking or satisfaction and of falsemaking or violation play a central role, though applied to declarative and imperative sentences. The very same notions, however, can be applied also to attitudinal objects. ${ }^{24}$ Truthmaker semantics provides a notion of

\footnotetext{
22 Jarvis (2012) mistakenly takes correctness to also apply to conative mental states such as intentions, pointing to the possibility of an intention being 'correctly realized'. But in correctly realized, correctly applies to the action that aims to realize the intention, not the intention, the mental state, itself.

23 The fact that correct evaluates actions that aim to satisfy a request or obligation, but cannot convey the fulfillment of the request or obligation is not only a conceptual truth about the direction of fit associated with satisfaction, but also a linguistic universal. The very same holds for normative predicates such as right, wrong, and German stimmen.

24 A rudimentary truthmaker view of intentionality (that is, not involving sentences, but mental states and cognitive and illocutionary acts) can also be found in Searle (1983). For the notion of a truthmaker see also Mulligan et al. (1984).
} 
content and of partial content, construed in terms of exact truthmaking or satisfaction (Fine 2017b, to appear a, b) Also those notions can be carried over straightforwardly to attitudinal objects (Sect. 5).

There are various motivations for truthmaker semantics, as opposed to possibleworlds semantics (Fine 2017b, to appear a, b). They include the interest in having a notion of partial content, a notion that also applies to attitudinal objects (Sect. 5). The semantic differences among satisfaction predicates and the notions they involve provide new motivations for truthmaker theory, now applied to attitudinal objects. Also the notion of a direction of fit goes along best with a truthmaker approach, by imposing norms on actions, not entire worlds.

\subsection{Modal objects and their satisfaction conditions}

There is another type of object besides attitudinal objects that displays satisfaction conditions. These are what I call (deontic) modal objects. ${ }^{25}$ Modal objects (of the deontic sort) are entities like obligations, needs, permissions, offers, and invitations. They are the entities that correspond to deontic modals and would be described by nominalizations of deontic modal predicates. But deontic modal objects also include (abstract) artifacts like laws and rules, which are independent of the availability of nominalizations in particular languages. Modal objects share the characteristics of attitudinal objects, characteristics that distinguish them from entities such as states, actions, and propositions. That is, modal objects enter similarity relations based on sameness of content (John's obligation being the same as Mary's means they are the same in content); they have a part structure strictly based on partial content (part of John's obligation can only be a partial content, not a temporal part of a state or event or a structural part of a proposition), and, most importantly, deontic modal objects have satisfaction conditions. Thus, an obligation or commitment may be satisfied, fulfilled, or complied with, and an offer or invitation taken up or accepted. Modal objects may be produced by the very same acts that produce illocutionary products, such as acts of requesting, promising, and permitting. But unlike illocutionary products, modal objects can last beyond the illocutionary act that may have established them. Thus, if Joe, being in a relevant position of power, asks Mary to work fulltime, then not only a request for Mary to work fulltime results, but also (under the right circumstances) an obligation for her to work fulltime, and that obligation may last way past the time of the request. A modal object produced by an illocutionary act shares its satisfaction conditions with the illocutionary product that the same act produces, but it generally has a different lifespan. ${ }^{26}$ Deontic modal objects have a world-word/mind direction of fit. That is, they can be satisfied (or violated) only by actions and impose a norm of correctness or legitimateness on actions.

\footnotetext{
25 There are other modal objects which I will set aside, such as epistemic modal objects (certainties, possibilities), abilities, and essences. See Moltmann (2017c) for discussion.

26 Some nouns are polysemous, standing for an illocutionary product or a modal object, for example permission, offer, and invitation.
} 
Not all attitudinal and modal objects that have satisfaction rather than truth conditions go along with the predicates be satisfied or be fulfilled. Attitudinal and modal objects can be 'satisfied' or 'fulfilled' only if their modal force is that of necessity rather than possibility. Attitudinal and modal objects with the modal force of possibility such as proposals, permissions, offers, and invitations cannot be 'satisfied' or 'fulfilled'. Instead, a proposal, a permission, and an offer may be 'taken up' and an invitation 'accepted'.

Also actions of satisfying permissions, offers, and invitations are evaluated differently from the satisfiers of requests and obligations. An action of taking up a permission, offer, or invitation is 'legitimate', whereas an action of satisfying a request or obligation is 'correct'.

What distinguishes proposals, permissions, offers, and invitations from requests and obligations is that they cannot be violated. Not taking up an offer or accepting an invitation is not a violation, but not satisfying a demand or fulfilling a promise is. Moreover, whatever action is performed in virtue of which the demand or request fails to be satisfied, that action is a violator of the request or demand. Attitudinal and modal objects of possibility may have 'satisfiers', as I (misleadingly) call them, but they cannot have violators (Moltmann 2015b, 2017c).

This difference is reflected not only in the different satisfaction predicates applicable to the two sorts of attitudinal and modal objects. It is also reflected in the absence of any predicates of violation applicable to permissions, offers, and requests. Obligations can be violated or contravened, and rules or laws can be broken. Offers and invitations can be declined or refused, but that does not amount to a violation. The predicate ignore conveys violation with modal objects of necessity, but with modal objects of possibility it conveys simply failure to satisfy such an object. Ignoring a permission does not mean violating it, but ignoring a command or request means that. The difference in modal force is also reflected in the way satisfiers are evaluated. An action of taking up a permission would not be 'correct', but 'legitimate'. Note that by having only satisfiers and no violators, attitudinal and modal objects of possibility can only bear the equivalent of truth (that is, satisfaction), not that of falsehood.

This difference between modal objects of necessity and of possibility means that modal objects like requests, commands, commitments, and obligations have as their content both a set of actions that are satisfiers and a set of actions that are violators, whereas modal objects like invitations, permissions, and offers have only a set of satisfiers. More accurately, modal objects of necessity should be assigned as their content a pair consisting of a non-empty set of possible satisfiers and of a non-empty set of possible violators, whereas modal objects of possibility a pair consisting of a nonempty set of possible satisfiers and an empty set of possible violators.

\subsection{World-word/mind direction of fit for attitudinal objects without actions as satisfiers}

There are cases where appeal to the direction of fit is not straightforward and thus cannot immediately explain the choice of the satisfaction predicate. For example, nonfactive attitudinal objects associated with a positive emotion or preference (hopes, 
desires) do not have truth conditions, but fulfillment conditions. Hopes and desires cannot be said to be true or false, but they can be fulfilled or unfulfilled ${ }^{27}$ :

(31) John's hope/desire that he would win yesterday was fulfilled.

Why do hopes and desires have satisfaction conditions rather than truth conditions? Certainly hopes and desires do not always require actions to satisfy them, unlike requests and commands.

Does this mean that they have a word-word/mind direction of fit? If so, there would not be a correlation of the two directions of fit with satisfaction conditions versus truth conditions.

One might suggest that instead of the direction of fit, it is the future-orientedness of hopes and desires that makes predicates like be satisfied or be fulfilled available. ${ }^{28}$ However, fears, which tend to be equally future-oriented, do not accept be fulfilled, and neither does future-oriented believe:

(32) a. ??? John's fear that he would lose was fulfilled.

b. ??? John's belief that he would win was fulfilled.

There is a better explanation why positive emotive attitudes go with be fulfilled rather than be true having to do with what actually sets up a direction of fit. Positive emotive attitudinal objects like hopes and desires imply a positive emotive response to their satisfaction (under normal circumstances), and reaching that positive response requires for a part of the world to make such attitudinal objects true, rather than the attitudinal object aiming to represent the world. The positive emotive response that a hope is directed toward constitutes a kind of norm or purpose and as such imposes a requirement on the world, rather being subject to a requirement itself. By contrast, a merely doxastic attitudinal object such as a belief has as its norm or purpose the accuracy of the representation only and that imposes a requirement on the belief rather than on the world. Thus, hopes and desires, even though they do not require

\footnotetext{
27 This holds at least if they are they are future-oriented, rather than directed to the past as below:

(i) ??? John's hope that his wife was not his cousin has fulfilled itself.
}

Interestingly, a future-oriented hope can 'become true', though a present-oriented hope can neither 'be true' nor 'become true':

(ii) a. John's hope that he would win became true.

b. John's hope that the key had remained in the lock was fulfilled/??? was true/??? became true.

By contrast, predictions, which can only be future-oriented, can always be fulfilled or become true (though, again, they could not 'be true'). See Fn 13. This means that become true does not relate to epistemic uncertainty regarding the present or past, but metaphysical indeterminacy of the future.

28 There is a common characteristic of attitudinal objects with a world-word/mind direction of fit and future-oriented attitudinal objects, given an open, branching future. That is that at the time at which those attitudinal and modals objects exist, there will be different actions or states of affairs in different future stages of the (actual) world that would satisfy the attitudinal object. This is not the case for past or present-directed attitudinal objects (beliefs, claims, hopes) not even for those that could have several truthmaking states of affairs. Given truthmaker semantics, disjunctive or existentially quantified beliefs may have several states of affairs that make them (actually) true. Thus, John's disjunctive belief that Joe invited Mary or Bill would be made true both by an actual situation of Joe's inviting Mary and an actual situation of Joe's inviting Bill. These two situations would also both make true Bill's existentially quantified belief that Joe invited someone. The two situations, however, would be part of the same current or past stage of the world. 
actions to be their satisfiers, involve a world-word/mind direction of fit, rather than the word/mind-world direction of fit of merely doxastic attitudinal objects.

\subsection{Satisfaction conditions for intentions and decisions}

Attitudinal objects such as intentions and decisions are generally taken to involve a world-word/mind direction of fit. But the satisfaction of intentions and decisions is not conveyed by predicates like is satisfied or is fulfilled. Rather decisions are 'implemented' or 'executed' and intentions 'realized'. What distinguishes requests and orders from intentions and decisions is the normative aspect that goes along with the former, but not the latter. Requests and orders impose a kind of social norm on actions performed in recognition of them, in the sense that they impose a norm or purpose on another person's actions. This is not so for decisions and intentions: not realizing a decision or intention does not violate a norm imposed by someone else, but simply frustrates the aim of one's own intention or decision. Social norms are imposed only when an addressee is involved in the satisfaction of the attitudinal object. Requests can be 'fulfilled' because here one agent (the speaker) sets up a teleological norm to be fulfilled by another (the addressee). Promises can be 'fulfilled' because with a promise a speaker declares and thus shares with the addressee a norm that her actions will be subject to. ${ }^{29}$

To summarize, the semantic differences among satisfaction predicates reflect the presence or absence of violators as well as differences in the sorts of teleological norms imposed on the (exact) satisfiers of attitudinal objects. These semantic differences could not be formulated if attitudinal and modal objects were just assigned a set of worlds as their content. Rather they support a truthmaker approach to the content of attitudinal and modal objects.

\section{Predicates of validity}

Deontic modal objects like obligations, permissions, offers, as well as rules and laws have another truth-related dimension, namely validity. Predicates of validity include is valid, obtain, and hold. Validity is linked to existence, but also to truth.

Validity is the way of existence, the mode of being, of deontic modal objects. Thus, the validity of a modal object (at a time) amounts to the existence of the modal object (at the time) ${ }^{30}$ :

(33) a. The obligation for Mary to work still holds.

b. The permission/offer for Mary to use the house is still valid.

But validity is also linked to truth. Thus, the validity of a modal object amounts to the time-relative truth of the corresponding modal sentence or, equivalently, the truth of

\footnotetext{
29 Of course one can promise something to oneself. In that case, the agent acts in two roles, as receiver of the declared norm and the agent to fulfill it.

30 Validity in a way is also the mode of being of 'real' proofs: a proof is 'real' just in case it is valid. As such, validity coincides with correctness: a proof is valid just in case it is correct. See also Löf (1987) and Fn 10.
} 
the corresponding tensed modal sentence. Thus (33a) is, roughly, equivalent to (34a) and (34b), and (33b) to (35a) and $(35 b)^{31}$ :

(34) a. That Mary still has to work is true.

b. That Mary has to work is still true.

(35) a. That Mary may still use the house is true.

b. That Mary may use the house is still true.

For modal objects that are laws, rules, and or conditions the same holds for the predicate obtain:

(36) a. The law that one must have a passport still obtains.

b. That one must have a passport is still true.

Validity is linked not only to existence (as the mode of being of deontic modal objects) and to truth (of the corresponding modal sentence). It is also linked to satisfaction: only modal objects that have satisfaction conditions can have validity. There is moreover a close connection between validity and correctness: if a modal object (of necessity) is valid, then actions satisfying it are correct. ${ }^{32}$ The validity of a modal object thus imposes an action-guiding norm on its satisfiers. Validity, unlike truth for truth-directed attitudinal objects, does not constitute a norm for the modal object itself. That is, the correctness of a modal object does not consist in its validity, and, as it was already noted, it does not consist in its satisfaction either.

\section{Partial truth, correctness, satisfaction, and validity}

Truth and the more general notions of correctness and of satisfaction as well as the related notion of validity permit partial application, resulting in notions of partial truth in the sense of Yablo (2015), as well as partial correctness, partial satisfaction, and partial validity (Moltmann 2017a). Linguistically, this is reflected in the use of adverbials like partly modifying predicates of truth, correctness, satisfaction, and validity in the examples below:

31 It may be tempting to view the existence statements in $(33 a, b)$ as 'something-from-nothing inferences' from modal sentences, introducing a pleonastic entity (Schiffer 2003). However, this would not account for validity as the mode of being of the modal object, and it would fail to capture the modal object's satisfaction conditions, as well as the correctness of actions satisfying it.

32 Validity may also apply to products of declarative illocutionary acts:

(i) The declaration of war is still valid.

It may also apply to the abstract state that goes along with the declaration:

(ii) The state of war still obtains.

The abstract state is the obtaining of the declared condition at a particular time and space. See Moltmann (2013b) for more on the notion of an abstract state.

Unlike the products of declarative illocutionary acts, abstract states can only 'obtain', but not be 'valid'. Existence for abstract states amounts to the obtaining of a condition at a particular location (when established by acts of declaration). 
(37) a. John's belief is partly true.

b. John's claim is partly correct.

c. Mary's desire was partly satisfied.

d. The offer was partly taken up.

e. The offer is now only partly valid.

Partly as a predicate modifier in (37) relates to the content-based part structure of an attitudinal object. Thus, (37a)-(37e) are equivalent to (38a)-(38e):

(38) a. Part of John's belief is true.

b. Part of John's claim is correct.

c. Part of Mary's desire was satisfied.

d. Part of the offer was taken up.

e. Only part of the offer is now valid.

Also agent-related predicates of satisfaction allow for partiality:

(39) a. John partly satisfied the demand.

b. John partly followed Mary's advice.

The notion of partial satisfaction shows, again, the importance of distinguishing, in terms of their ability of having violators, illocutionary products of the sort of orders from those of the sort of offers. Partial (but not complete) fulfillment of an order goes along with partial ignorance or violation of the order, whereas partial (but not complete) taking up of an offer does not go along with any sort of violation. Failure to fulfill part of an order is partly violating it, whereas failure of taking up part of an offer is no violation of any sort.

Also modal objects allow for partial satisfaction:

(40) a. John partly fulfilled his obligation.

b. John partly followed the law/the rule.

Modal objects display a part structure based on partial content as well. When the part of-construction applies to a modal object, it picks out a partial content (rather than the temporal part of a state), as in the following examples ${ }^{33}$ :

(41) a. Part of John's obligation is to help Mary.

b. Part of the offer is to use the house in summer.

c. Part of the law concerns children.

Both satisfaction and validity of a modal object may be partial. The obligation for Mary to work on weekends may be satisfied only partially, and it may obtain only in part. An offer may hold only partially, and it may be taken up only in part. Both validity and satisfaction thus require a notion of partial content for their bearers.

\footnotetext{
33 There are non-deontic modal objects that in a way display a part structure based on partial content. These are entities of the sort of abilities, habits, implicit rules, and dispositions (Moltmann 2017a). With them, part of picks out part of the constitutive conditions making up the modal objects (as in part of John's special ability, part of John's habit). Of course, modal objects of the sort of abilities and habits cannot be true or false or even satisfied or not satisfied, but they can be manifested and partly manifested. An activity that is a partial manifestation of an ability is a manifestation of part of the ability.
} 
Partial validity cannot be reduced to partial truth. That is, the validity of part of a modal object cannot be reduced to the partial truth of a statement of the modal object's validity. Thus (42a) is not equivalent to (42b) nor is (43a) to (43b):

(42) a. The students fulfilled part of the requirement.

b. That the students fulfilled the requirement is partly true.

(43) a. The police force ignored part of the order.

b. That the police force ignored the order is partly true.

(42a) cannot have a reading on which part of the students fulfilled the requirement, but (42b) can have such a reading. Similarly, (43a) cannot have a reading on which part of the police force ignored the order, but (43b) can have such a reading.

Truthmaker semantics provides a straightforward notion of partial content (Yablo 2015; Fine 2017b):

(44) For sets $A$ and $B$ of situations or actions, $B$ is a partial content of $A$ iff every satisfier of $A$ contains a satisfier of $B$ and every satisfier of $B$ is contained in a satisfier of $A$.

The notion of a partial content of an attitudinal or modal object $o$ can then be defined as below, where $\operatorname{sat}(o)$ is the set of satisfiers of $o^{34}$ :

(45) A set $B$ of situations or actions is a partial content of an attitudinal or modal object $o$ iff $B$ is a partial content of $\operatorname{sat}(o)$.

With this notion of partial content, the two notions of partial satisfaction (truth) and partial validity can be formulated as follows:

(46) a. An (attitudinal or modal) object $o$ is partially satisfied (true) iff there is an actual situation or action $s$ and a partial content $B$ of $o$ such that $s \in B$.

b. A (potential) modal object $o$ is partially valid if there is a partial content $B$ of $o$ such that for some (potential) modal object $d$ that is part of $o, d$ is valid (exists) and $B=\operatorname{sat}(d)$.

(46b) is a condition on potential modal objects, modal objects that may or may not obtain or be valid. (46b) presupposes that for every partial content $B$ of a potential modal object $o$, there is a potential modal object that is part of $o$ and has $B$ as its (complete) content.

\footnotetext{
34 One motivation for Fine's (2017b, to appear a, b) notion of partial content is to account for the invalidity of the inferences below (Ross' paradox):

(i) Take an apple!

Take an apple or the gold!

Fine takes the consequence relation among imperatives as in (i) to be the relation of partial content, defined as follows. Imperative $B$ is a consequence of imperative $A$ iff every satisfier of $A$ contains a satisfier of $B$ and every satisfier of $B$ is contained in a satisfier of $A$. Fine (to appear a, b) explains the invalidity of the corresponding inference with deontic may in a somewhat similar way:

(ii) You may take an apple.

You may take an apple or the gold.
} 


\section{Truth predicates and sentential subjects}

We have seen that truth predicates and their variants - predicates of correctness, satisfaction, and validity - apply to attitudinal and modal objects, entities that come with essential representational and, to an extent, normative properties. However, this generalization was established on the basis of sentences with noun phrases as subjects. The question, then, is how are truth predicates to be understood when they apply to that-clauses as subjects, as below:

(47) That Berlin is the capital of Germany is true.

There are two important generalizations about truth predicates with sentential subjects as in (47). First, the sentential-subject construction in (47) systematically alternates with the extraposition construction, as below:

(48) It is true that Berlin is the capital of Germany.

This alternation in fact holds for all predicates that take sentential subjects. That is, all predicates that take a clause as subject (is important, is likely, is nice, is known, was discovered...) also allow for the clause to be extraposed, as in (48).

Second, sentential subjects generally can be replaced by special quantifiers and pronouns such as something or that:

(49) a. Something is true.

b. That is true.

Quantifiers and pronouns like something and that are special in that they can take the place of predicative, intensional, and other nonreferential complements. They are thus not themselves indicators of the referentiality of the expression they may replace, but instead may have a nominalizing function, introducing new objects into the semantic structure of sentences that would not have been available otherwise (Moltmann 2003a, 2013a, 2017c).

The philosophical literature, as was mentioned, has mainly focused on truth predicates with sentential subjects. This focus has given rise to particular views about the notion of truth - in particular deflationism and minimalism - which are based on the assumption that that-clauses are proposition-denoting nominalizations of sentences. I will come to those views and the way they are challenged by the present perspective in the next section.

Another view that the focus on true with sentences has given rise to is the view that it is true that is primarily an operator or connective rather than is true being a predicate applied to an object (Mulligan 2010). When considered a connective or operator, it is true that would have no semantic contribution or at best would just serve to shift the evaluation of the subsequent clause to a different time or circumstance. Linguistically, this view, when applied to the actual linguistic form of it is true-sentences, is hard to maintain. First of all, it is true that does not form a constituent; rather that and the clause that follows that do. Moreover, the view gives priority to the extraposed form, when in fact extraposition of sentential subjects is always available even for predicates 
like is nice and is hard to believe, which could hardly be considered 'connectives' or 'operators' (Moltmann 2015a). In fact, the availability of the extraposed form with true does not specifically support true not acting as a predicate. There are predicates that allow only for the extraposed form, for example seem and appear (it seems that $\mathrm{S}$, * That $\mathrm{S}$ seems, it appears that $\mathrm{S}$, * That $\mathrm{S}$ appears), and the general explanation is that those predicates select CPs (roughly, sentential arguments), whereas those that allow for subject clauses select DPs (roughly, referential arguments) (Alrenga 2005). This means that true actually selects a DP (a referential argument) rather than a sentential argument (a that-clause), even if the embedded clause is extraposed. The that-clause, which is a CP, will thus not act as a referential term standing for the object that true applies to. Rather the DP, which is syntactically required in subject position, will do so.

How then does the that-clause relate to the DP in subject position with the predicate true? There are roughly two views in the literature about the syntactic position of the apparent subject clause and its relation to the DP in subject position. On one view, argued for by Koster (1978), the subject clause is in fact in topic position. This means that it would just be linked to an empty nominal element $e_{N}$ in the subject position in the structure below:

\section{(50) $\left[[\text { That Paris is the capital of France }]_{\mathrm{TOP}}\left[\left[\mathrm{e}_{\mathrm{N}}\right]_{\mathrm{DP}}[\text { is true }]_{\mathrm{VP}}\right]\right]_{\mathrm{CP}}$}

The topic position does not require a referential expression, but also allows for predicates (such as really happy in Really happy he will never be). Only the empty DP in subject position will refer to the object that true is predicated of. An empty DP in subject position in general may stand for different sorts of objects, depending on the type of object the predicate requires; the that-clause in topic position will just serve to characterize the object's content.

On another view, recently pursued by Kastner (2015), a subject clause will in fact just be a part of the DP in subject position modifying an empty nominal $e_{N}$, as below:

\section{$\left[\left[\mathrm{e}_{\mathrm{N}} \text { that Paris is the capital of France }\right]_{\mathrm{DP}}[\text { is true }]_{\mathrm{VP}}\right]_{\mathrm{CP}}$}

Such a DP construction would overtly be of the sort the claim that $\mathrm{S}$, the fact that $\mathrm{S}$, or the proposition that $\mathrm{S}$. On that view, again, the that-clause would have the semantic role of just characterizing the object the entire DP stands for and that the predicate will apply to, rather than acting as a referential term referring to it.

Without going into the details that motivate the two views and a comparison among them, clearly on either view true with a that-clause requires a referential category (DP) in subject position (unlike on either view, seems and appears). This means that true should perform its ordinary semantic role as a predicate applying to an object even when it applies to a that-clause.

What sort of object does the subject DP with is true stand for? It appears that true with a that-clause does not apply to a proposition, but rather to an attitudinal object, just like true with an overt DP (referential NP). More precisely, true with a that-clause applies to a contextually given claim or suggestion whose content is given by the thatclause. The semantic evidence comes from the applicability of the normative truth 
predicate correct to that-clauses. Correct, which was not applicable to propositions, is unproblematic with that-clauses (in subject position and when extraposed), and then, as with beliefs and claims, it conveys truth (and just truth):

(52) a. That John is the director is correct.

b. It is correct that John is the director.

As such, correct also permits modification by partly, requiring access to the partial content of a truth-directed attitudinal object:

(53) That John is in charge is partly correct.

The syntactic and semantic arguments taken together make it implausible that thatclauses with the predicate true stand for abstract propositions, the semantic values of sentences. Rather they support the view that that-clauses with true as predicate serve to characterize a claim, suggestion, or hypothesis to which the speaker refers with the silent (or at least partly silent) DP in the subject position. This interpretation would correspond to a syntactic structure in which the subject DP contains a silent head noun for an assertive illocutionary product and the that-clause appears in or relates to the position following the silent noun for the illocutionary product. ${ }^{35}$ Note that the claim or suggestion referred to need not be an actual one: it may be a kind of claim or suggestion, what could be referred to as 'the claim that $S$ ' or 'the suggestion that $S$ '. Natural language permits reference to particular attitudinal objects (John's claim that $\mathrm{S}$ ) just as it permits reference to kinds of attitudinal objects (the claim that $\mathrm{S}$ ) (Moltmann 2003b, 2013a, 2014, 2017c).

A final issue is how special quantifiers or pronouns like something or that as in (49a, b) should be understood. Such quantifiers and pronouns are special in that they can take the place of various nonreferential occurrences of expressions (predicative and intensional complements of verbs, for example). They arguably act semantically as nominalizing expressions and as such stand for attitudinal objects or kinds of them

\footnotetext{
35 There is a puzzle for this syntactic account of subject clauses, though, that still needs an explanation. This is a difference between full DPs with a that-clause modifier and DPs with a silent head noun. That-clauses in subject position are not referentially independent, unlike what the account would predict. That is, what kind of entity a that-clause in subject position stands for depends strictly on the predicate. This is illustrated in the understanding of the evaluative predicate nice below:
}

(i) a. That Mary got elected is nice.

b. The fact that Mary got elected is nice

Sentence (ia) allows only for a reading on which nice evaluates a fact, making it equivalent to (ib) even though nice could in principle evaluate a proposition (as in the proposition that $\mathrm{S}$ is nice) or a possibility (as in the possibility that $S$ is nice).

Other predicates may apply only to possibilities, for example exclude. Thus (iia) can only be understood as equivalent to (iib), even though there is a sense in which facts and claims can be excluded too:

(ii) a. That John might get elected is excluded.

b. The possibility that John might get elected is excluded.

Only in the presence of a suitable predicate can a that-clause in subject position stand for a contextually given claim or suggestion, for example with true or correct. This means that with (apparent) subject clauses the silent head noun of the subject DP cannot be freely chosen, unlike the overt head noun in the construction the claim that $\mathrm{S}$. 
when they occur with predicates that also take that-clauses (Moltmann 2003a, b, 2013a, 2017c).

\section{Truth predicates in natural language and deflationist and minimalist views of true}

One central issue in the philosophical discussion of truth is the status of true as a predicate expressing a property. The last section made clear that true syntactically and semantically acts as a predicate even with that-clauses. Another issue is whether true as a predicate expresses a property in any substantial sense or whether it better goes along with a deflationist or minimalist account of some sort (Horwich 1990; Künne 2003). In what follows, I will argue that the overall view of truth and related notions that is reflected in truth-related predicates in natural language is incompatible with a deflationist or minimalist view of truth.

Deflationists and minimalists deny that true expresses a real property, but they do not necessarily make claims about the syntactic status of true. Thus, Horwich's (1990) version of deflationism only maintains that what constitutes having the concept of truth is the knowledge of the equivalence schema below, where [S] is a nominalization function (roughly corresponding to the complementizer that) ${ }^{36}$ :

(54) $[($ that $) \mathrm{S}]$ is true iff $\mathrm{S}$.

As stated in (54), this deflationist view still makes some semantic assumptions, though. First, it gives priority to the clausal construction. (54) is applicable only when true applies to a that-clause and not when it applies to a referential NP. Moreover, (54) treats a that-clause as a proposition-referring term. Given (54), the application of the truth predicate amounts to the denominalization of the proposition-referring term (a that-clause) and the use of the sentence thus obtained.

In addition, (54) could not be extended to the full range of truth-related predicates. First of all, a schema like (54) could not apply to the normative predicate correct conveying truth when applied to some objects, but not others. Correct does not even apply to propositions, but only to entities like beliefs and assertions.

Moreover, (54) cannot be extended to predicates of satisfaction, which is particularly problematic if predicates of satisfaction are considered predicates that include true as a special case. For a schema like (54) to cover predicates of satisfaction, it would have to apply to what amounts to the nominalization of an imperative, let's say to a term for a request. But the satisfaction of a request does not amount to the use of an imperative. The latter serves to make a request, not to satisfy it. The deflationist account, moreover, could not apply to agent-related satisfaction predicates.

There is also a general issue with what true is taken to apply to in (54). It is far from clear that there is such a thing as a notion of an abstract proposition-a truth bearer - that is not itself constituted by the notion of truth and the intentionality of agents (Boghossian 2010). Truth is intimately linked to intentionality and the ability to represent, on a par with satisfaction. Attitudinal objects as agent- and mind-dependent objects reflect that link, abstract propositions don't.

36 The following critique also applies to Künne's (2003) minimalist account. 


\section{Conclusion}

The aim of this paper was to show that a closer look at the semantic behavior of truth predicates and their variants provides important insights into the notion of truth and related notions. The core of natural language, the paper argued, reflects the view that attitudinal objects are the bearers of truth or satisfaction conditions, rather than propositions, as on the standard view. This holds even when truth predicates apply to that-clauses. Furthermore, natural language displays a notion of truth that has the status of a norm associated with certain types of representational objects, rather being action-guiding. Finally, the different types of satisfaction predicates give support for a truthmaker theory being associated with the notions of truth and satisfaction, as does the possibility of partial truth, partial satisfaction, and partial validity.

If attitudinal objects rather than propositions act as the primary truth bearers, this will raise the question of the semantics of attitude reports. On the standard view, attitude reports like John believes that $\mathrm{S}$ involve propositions as the semantic values of thatclauses, which will act as the relata of a two-place attitudinal relation (the relation of believing). However, there are various linguistic and philosophical motivations for an alternative view on which attitudinal objects, rather than propositions, play a central role in the semantics of attitude reports. ${ }^{37}$

Acknowledgements This paper has benefitted greatly from comments of two referees and the editor of the special issue Jeremy Wyatt. It also has benefitted from comments by Rögnvaldur Ingthorsson, Bruno Leclercq, Paolo Leonardi, Benjamin Nelson, and Stephen Yablo. Previous versions of the paper were presented at the workshop Truth, Contextualism, and Semantic Paradox at Ohio State University, Columbus, March 29-30, 2017 and the workshop Force, Content and the Unity of the Proposition at the University of Vienna, May 19-20, 2017, and I would like to thank the audiences for discussion.

\section{References}

Alrenga, P. (2005). A sentential subject asymmetry in english and its implications for complement selection. Syntax, 8, 175-207.

Asher, N. (2010). Lexical Meaning in Context: A Web of Words. Cambridge: Cambridge University Press. Boghossian, P. (2003). The normativity of content. Philosophical Issues, 13, 31-45.

Boghossian, P. (2010). Our grasp of the concept of truth: Reflections on Künne. Dialectica., 64, 553-563. Cresswell, M. J. (1986). Why object exists, but events occur. Studia Logica, 45, 371-375.

Fine, K. (2017a). Naïve metaphysics. In J. Schaffer (Ed.), Philosophical issues (Vol. 27, pp. 98-113).

Fine, K. (2017b). Truthmaker semantics. In B. Hale, C. Wright, \& A. Miller (Eds.), A companion to the philosophy of language. Chichester: Wiley (online).

Fine, K. (to appear a). Compliance and command I. Review of Symbolic Logic (to appear).

Fine, K. (to appear b). Compliance and command II'. Review of Symbolic Logic (to appear).

Gibbard, A. (2005). Truth and correct belief. Philosophical Issues, 15, 338-350.

Glüer, K., \& Wikforss, A. (2009). Against content normativity. Mind, 118, 31-70.

Grover, D. L., Camp, J. L., \& Belnap, N. D. (1975). A prosentential theory of truth. Philosophical Studies, 27, 73-125.

Hacker, P. M. S. (1982). Events, ontology, and grammar. Philosophy, 57, 477-486.

37 On that view, that-clauses semantically act as predicates of attitudinal objects and the sharing of a propositional content consists in two agents engaging either in attitudinal objects that are closely similar (that is, the same in content) or in the same kind of attitudinal object (Moltmann 2003b, 2013a, 2014, 2017c). 
Horwich, P. (1990). Truth. Oxford: Blackwell.

Jarvis, B. W. (2012). Norms of intentionality: Norms that don't guide. Philosophical Studies, 157, 1-25.

Kastner, I. (2015). Factivity mirrors interpretation: The selectional requirements of presuppositional verbs. Lingua, 164, 156-188.

Koster, J. (1978). Why subject sentences don't exist. In J. S. Kayser (Ed.), Recent transformational studies in European languages (pp. 53-64). Cambridge, MA: MIT Press.

Künne, W. (2003). Conceptions of truth. Oxford: Clarendon Press.

Löf, P. M. (1987). Truth of a proposition, evidence of a judgment, validity of a proof. Synthese, 73, 407-420.

Moltmann, F. (2003a). Nominalizing quantifiers. Journal of Philosophical Logic, 32, 445-481.

Moltmann, F. (2003b). Propositional attitudes without propositions. Synthese, 135, 70-118.

Moltmann, F. (2013a). Abstract objects and the semantics of natural language. Oxford: Oxford University Press.

Moltmann, F. (2013b). On the distinction between abstract states, concrete states, and tropes. In A. Mari, C. Beyssade, \& F. Del Prete (Eds.), Genericity (pp. 292-311). Oxford: Oxford University Press.

Moltmann, F. (2013c). The semantics of existence. Linguistics and Philosophy, 36(1), 31-63.

Moltmann, F. (2014). Propositions, attitudinal objects, and the distinction between actions and products. Canadian Journal of Philosophy, 43(5-6), 679-701.

Moltmann, F. (2015a). Truth predicates in natural language. In D. Achourioti, et al. (Eds.), Unifying the philosophy of truth (pp. 57-83). Dordrecht: Synthese Library Springer.

Moltmann, F. (2015b). 'A predicativist semantics of modals based on modal objects'. In T. Brochagen, F. Roloefson, \& N. Theiler (Eds.) Proceedings of the 15th Amsterdam Colloquium (pp. 296-302), ILLC, Amsterdam.

Moltmann, F. (2017a). Partial content and expressions of part and whole. Discussion of Stephen Yablo: Aboutness. Philosophical Studies, 174(3), 797-808.

Moltmann, F. (2017b). Natural language ontology. In Oxford encyclopedia of linguistics. Oxford: Oxford UP. http://linguistics.oxfordre.com/view/10.1093/acrefore/9780199384655.001.0001/acrefore-97801 99384655-e-330.

Moltmann, F. (2017c). Cognitive products and the semantics of attitude verbs and deontic modals. In F. Moltmann \& M. Textor (Eds.), Act-based conceptions of propositional content. Contemporary and historical perspectives. New York: Oxford University Press.

Moltmann, F. (2017d). Levels of linguistic acts and the semantics of saying and quoting. In S. L. Tsohatzidis (Ed.), Interpreting Austin: Critical essays (pp. 34-59). Cambridge: Cambridge University Press.

Moltmann, F. (to appear). Natural language and its ontology. In A. Goldman \& B. McLaughlin (Eds.), Metaphysics and cognitive science. Oxford: Oxford University Press.

Mulligan, K. (2010). The truth predicate vs the truth connective. On taking connectives seriously. Dialectica, 64, 565-584.

Mulligan, K., Simons, P., \& Smith, B. (1984). Truthmakers. Philosophy and Phenomenological Research, 44, 287-321.

Pustejovsky, J. (1995). The generative lexicon. Cambridge, MA: MIT Press.

Ramsey, F. P. (1927). Facts and propositions. Aristotelian Society Supplement Volume 7, pp. 153-170. Reprinted in D. H. Mellor (ed.): F. P. Ramsey, Philosophical Papers, Cambridge: Cambridge University Press 1990, pp. 34-51.

Schiffer, S. (2003). The Things we Mean. Oxford UP: Oxford.

Searle, J. (1969). Speech acts. Cambridge: Cambridge UP.

Searle, J. (1983). Intentionality. Cambridge: Cambridge UP.

Strawson, P. (1959). Individuals. An essay in descriptive metaphysics. London: Methuen.

Thomasson, A. (1999). Fiction and metaphysics. Cambridge: Cambridge UP.

Thomson, J. (2008). Normativity. Chicago: Open Court.

Twardowski, K. (1911). Actions and products. Some remarks on the borderline of psychology, grammar, and logic. In J. Brandl \& J. Wolenski (Eds.), Kazimierz Twardowski. On actions, products, and other topics in the philosophy. Rodopi, Amsterdam and Atlanta, 1999, pp. 103-132. Repitnted also in F. Moltmann \& M. Textor (2017).

Ulrich, W. (1976). An alleged ambiguity in the nominalizations of illocutionary verbs. Philosophica, 18(2), $113-127$.

Williamson, T. (2000). Knowledge and its limits. Oxford: Oxford University Press.

Yablo, S. (2015). Aboutness. Cambridge: MIT Press. 